\title{
The Cultural Economy of Auteurship in Independent Publishing: The Symbolic Success of the Photobook Ponte City
}

\author{
James Graham \\ Middlesex University
}

\section{Introduction}

As far as book publicity events go, it was somewhat out of the ordinary. Alongside subscribers to And Other Stories, a UK-based independent publisher specializing in translations of non-English literary fiction into English, an academic network interested in the work of South African writer and editor Ivan Vladislavić had been invited to copy-edit a section of his 1999 novel The Restless Supermarket and submit it to the author himself to be judged. The winner of the 'Restless Derby' would be announced at a book reading at Sussex University as part of a publicity tour promoting the novel's UK publication in the summer of 2014. As a member of said network, and at that time working on a project that happened to explore Vladislavićs influence as an editor, I was thrilled at the prospect of him casting his expert eye on my own editorial craft. I dutifully submitted my effort and booked a ticket for the event.

How to cite this book chapter:

Graham, J. 2017. The Cultural Economy of Auteurship in Independent Publishing: The Symbolic Success of the Photobook Ponte City. In: Graham, J. and Gandini, A. (eds.). Collaborative Production in the Creative Industries. Pp. 69-85. London: University of Westminster Press. DOI: https://doi.org/10.16997/book4.e. License: CC-BY-NC-ND 4.0 
Sadly I didn't win the 'Restless Derby' (I'll be the first to admit I still have plenty to learn as an editor). But along with everyone else who attended the event, including Vladislavić as far as I could tell, I enjoyed it immensely. Not only were we able to live out the kind of metatextual joke that hallmarks Vladislavić's fiction, we also got to hear him talk candidly about the making of the novel. This revealed a great deal about the impact the transformation of Johannesburg in the 1990s (the central subject of the book) had on his own career as an editor and writer. More significantly for what follows, however, he also spoke about his role in the making of Ponte City: a photobook by Mikhael Subotzky and Patrick Waterhouse published in 2014 that takes as its subject Johannesburg's most iconic residential building. But he didn't just refer to this book - which ostensibly had nothing to do with the publication or publisher of The Restless Supermarket - in passing. Rather, the Ponte City book ended up taking centre stage as Vladislavić took great delight in unboxing its various component parts (see fig. 5.1) and then reassembling them, by way of explaining his integral role as what he termed it's 'creative editor' (Penfold, 2014; 'The Restless Derby', 2014). He explained how his work had involved sifting through the huge archive of material Subotzky and Waterhouse collated in their six-year documentary project, identifying thematic assemblages of materials (not just the photographs but a cornucopia of 'found' material discarded by the towers' residents over the years, ranging from the love letters of migrant workers to

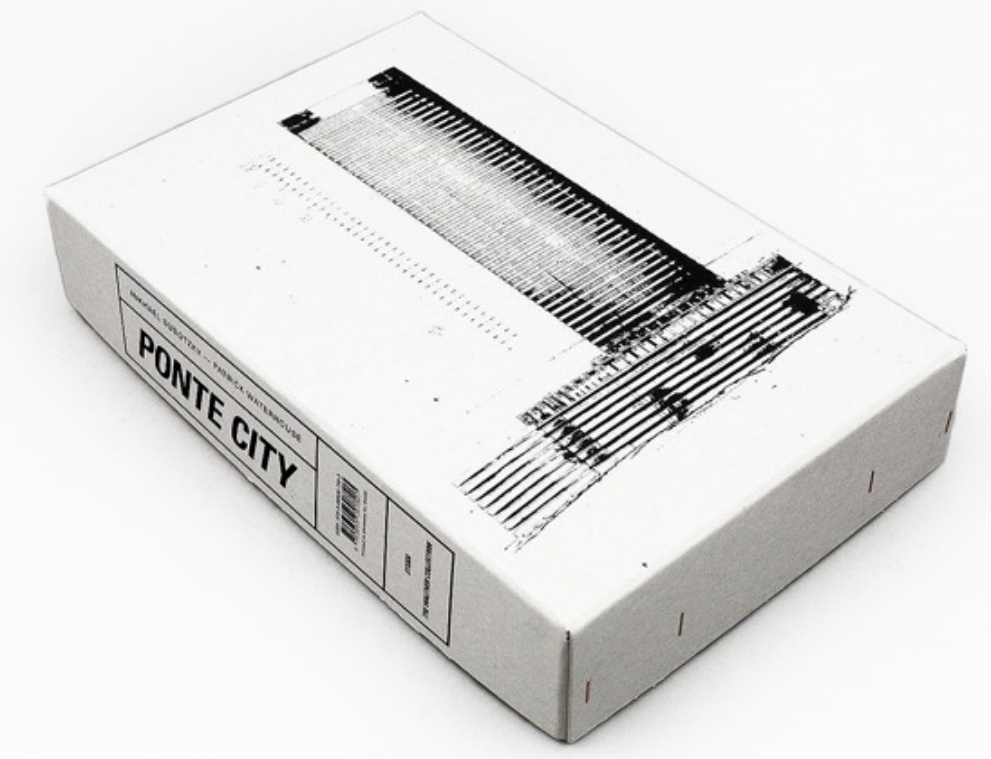

Figure 5.1: Ponte City, Steidl. 


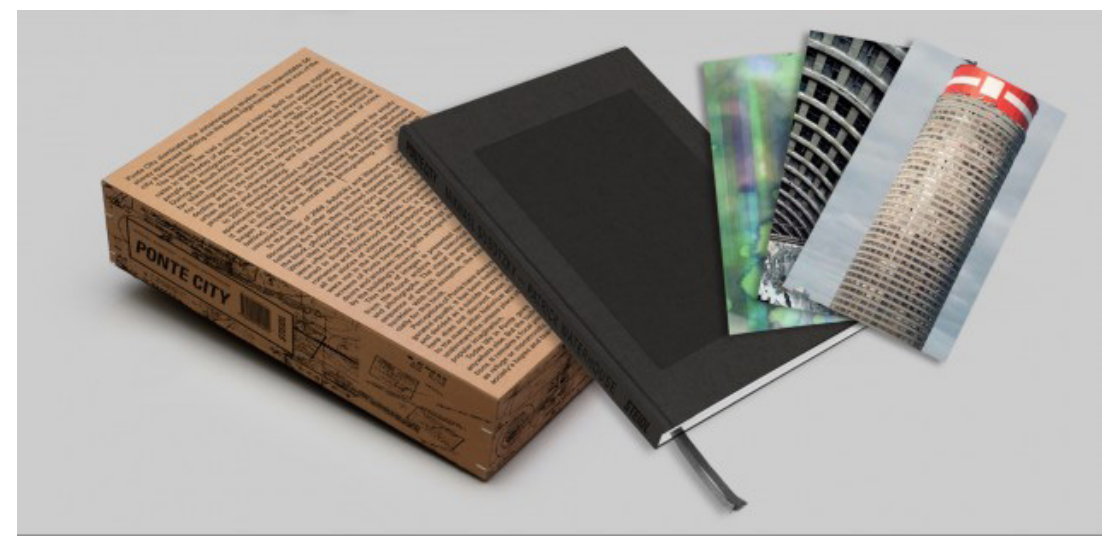

Figure 5.2: Ponte City 'unboxed'. The assemblage consists of a box file that contains within it: a 'traditional' photobook comprising of Subotsky's and Waterhouse's photographs and seventeen pamphlets written by a range of authors and illustrated with images of the photographs and found materials.

adverts for the apartment block), before writing three and commissioning (and of course editing) a further 14 short responses to accompany the main photobook section of the book (see fig. 5.3). He summarised his role as editor of Ponte City as 'conceptualizing and commissioning' the book, and he was clearly very proud of the result. ${ }^{2} \mathrm{He}$ was careful not to go as far as claiming co-authorship when he was asked about the extent of his creative input, but on a number of occasions he did refer to it as one of 'his' books. In addition to claiming a degree of creative ownership then, he also noted his pleasure in those aspects of the book's production with which he had not been directly involved, for instance in finding that the pamphlets he edited were designed and produced in such a way that they might be incorporated in the main photobook as interchangeable captions (see fig. 5.4). ${ }^{3}$

An event designed to cultivate an international consumer public (albeit a very modest one) around the UK publication of a celebrated South African author's 15-year-old novel turned into something quite different: a platform that promoted that and another book, authored by other people and produced by a different publisher. As much as Vladislavić was happy to talk about The Restless Supermarket and play along with the 'Restless Derby', he was evidently highly invested in this other book and keen to introduce it to 'his' public something that the And Other Stories founder Stefan Tobler was more than happy to facilitate, as it was he who had brought the book to the event.

In February 2015, three months before Ponte City went on display at the Photographers Gallery in London alongside the other works shortlisted for the 2015 Deutsche Börse Photography Prize, the most prestigious of its kind in Europe, Vladislavić was awarded a \$150,000 Windham-Campbell Prize from 


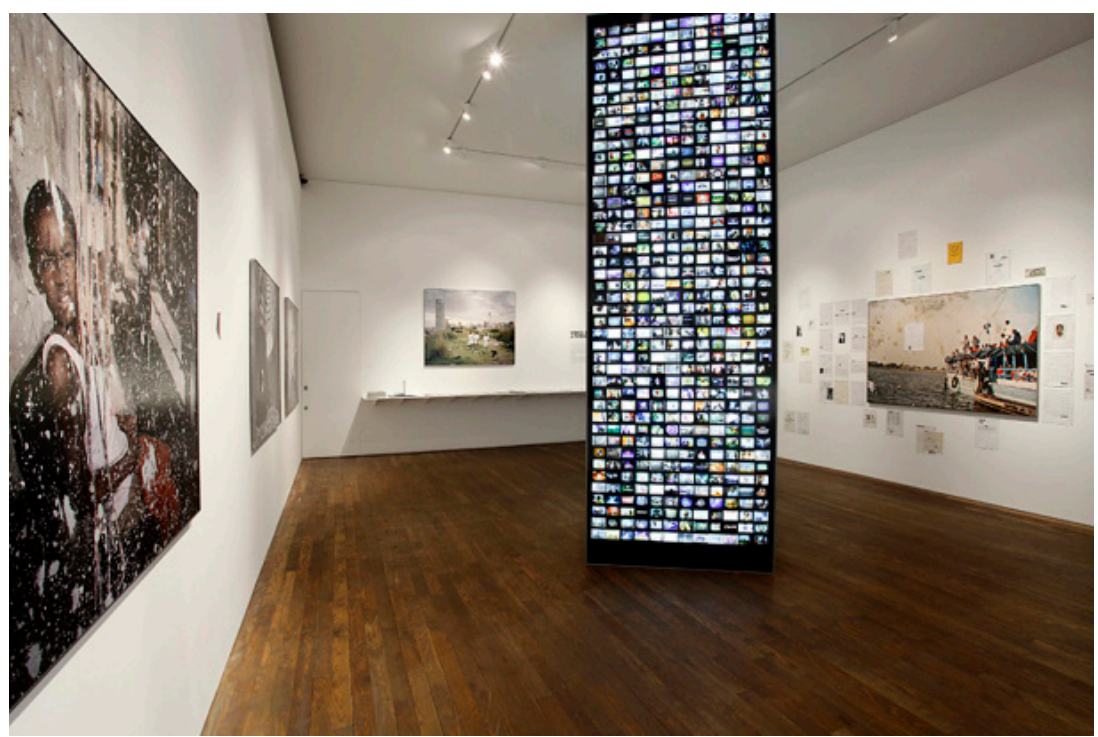

Figure 5.3: 'Ponte City' installation at The Photographers Gallery London, April 2015.

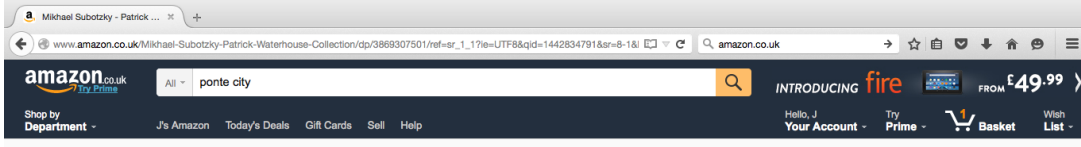

Books Advarced Search Best Selers New Releases Top Offers School Books Books Outtet Texibooks Browse Gerres Papertacks Audicbocks

(Back to search ressults for" "ponte oits"
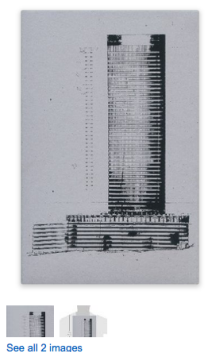

Mikhael Subotzky - Patrick Waterhouse: Ponte City (Walther Collection) Hardcover - 16 Jun 2014

by Nan Vladislavic (Author), Ramon Pez (Author)

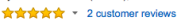

- See all formats and editions

Hardcover
$£ 54.40$

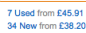

Want it Today, 6pm-10pm 2 Order it within 18 mins and choose Evening Dolivery at checkout Detalls

Mikhael Subotzky and Patrick Waterhouse worked at Ponte Cily, the iconic Johannesburg apartment building which is Africas talest residential skyscraper, for more than six years, They photographed the residents and documented the building every door, the view from every window, the image on every television screen. This remarkable body of photographs is presented here in counterpoint with an extensive archive of found material and historical documents. The visual story is integrated with a - Read more

Special Offers and Product Promotions

Figure 5.4: Ponte City - 'by' Ivan Vladislavić (Author) and Ramon Pez (Author). Screenshot taken 21 August 2015.

Yale University for his fiction, specifically to provide the autonomy necessary to pursue his writing unburdened of financial constraints. In May 2015, Subotzky and Waterhouse were announced as winners of the Deutsche Börse, elevating them to the global pantheon of contemporary visual artists. Within months 
of being recognised by a similarly global prize that would free him from the editorial work that had subsidised his writing career to that point, an art work Vladislavić had contributed to as a 'creative editor' was similarly recognised and its own authors set on a related path to artistic autonomy.

Without going as so far as to suggest a direct causal relationship between these separate symbolic successes, my argument in this chapter is that their correlation tells us a great deal about the increasingly vital role - both practical and promotional - played by the auteur figure in neoliberal economies of collaborative production. In the discussion that follows I use the examples of Vladislavić's UK publisher, And Other Stories, and the publisher of Ponte City, doyen of independent photobook publishing Gerhard Steidl, to examine the collaborative production practices in independent book publishing in a 'postdigital age' - a term used by Alessandro Ludovico (2012) to account for contexts in which print is being revitalised rather than replaced. These examples illustrate how niche sectors of the publishing industry project collaborative production as the kind of 'art world' Howard Becker (1982) famously outlined: where 'the artist thus works in the centre of a network of cooperating people, all of whose work is essential to the final outcome' (p. 25). As I show in this chapter, however, this convivial - as opposed to Bourdieu's (1993) competitive model of cultural production remains largely in thrall to a cultural economy dominated by the symbolic and economic capital invested in creative individuals (the author-brand, but increasingly also the auteur-brand), rather than the 'ethical value' (Arvidsson, 2013) generated among the networks through which the artwork is produced.

\section{Digital convergence and collaboration in independent publishing: And Other Stories}

The impact of what some commentators term 'digital disruption' (McQuivey, $2013,2015)$ on the publishing industry is most visible in the convergence of previously discrete creative activities in the mainstream of this industry. For almost two decades the business of publishing has been creeping ever closer to the edge of a tectonic rift. On one side of this rift the work of the traditional publisher remains essentially unchanged: the making and taking of books to market. However, increasingly this means the creation, promotion and dissemination of books in dynamic digital formats, but also the licensing of content for adaptation in other media (Murray, 2012). Yet even as digital production becomes normalised loud voices continue to argue that demand for the physical book, and the valuable synaesthetic culture it embodies, remains strong and indeed underpins rather than is superseded by wholesale digitization. 'Books persist', as Rebecca Walkowitz (2016) recently put it. The return to profitability of the UK bookstore chain Waterstones in 2015 provides some evidence for the claims long-made by managing director James Daunt that, after the initial '- 
disruption', there 'would be a natural point of equilibrium with digital reading that it would overshoot, then come back and settle down.' For Daunt, the future of the physical book and its traditional formats is rosy: 'books that you want to treasure, look after and sit on your bookshelf - the physical book is a better thing. You are left with a memory; you've got something that has an enduring value.' (quoted in Ruddick, 2015).

On the brave new world the other side of the rift, however, the cultural and economic role of books and the mediatory function of the publisher have evolved decisively. To survive, let alone flourish in a marketplace dominated by mega-tech businesses such as Google, Apple and Amazon on the one hand, and threatened with usurpation from below by the 'disruptive innovation' of long tail economics (Christensen, 1997) on the other, the publisher must now seek to remain profitable through the curation as opposed merely to the production of content. A prominent advocate for this shift is the digital publisher Michael Bhaskar, his argument encapsulated in the transition from the title of his 2013 book The Content Machine: Towards a Theory of Publishing from the Printing Press to the Digital Network to his recently published Curation: The Power of Selection in a World of Excess (2016). Hal Robinson (2012) has similarly argued that far from being the harbinger of doom, digital in fact heralds a renaissance in publishing - not just a rebirth, rather a full blown reprise of the specifically collaborative creativity that defined the epochal shift of the Renaissance period. For the 'publishing ecosystem' to thrive in the digital age, publishers need to concentrate on 'using converging media, encouraging consumers to communicate, listening to consumers and cultivating the content they're interested in, and coordinating creative collaboration among all involved.'(p. 8) Drawing on Robinson's discussion, Stefen Tobler (2013), founder of And Other Stories and UK publisher for Ivan Vladislavić's fiction, has suggested that independent publishing houses are particularly well positioned to take advantage of each of these aspects of digitization.

Tobler (2013) describes the genesis of And Other Stories as a social enterprise: a not-for-profit publishing venture that looked to capitalise on the passionate investment of publishing professionals as well as readers in the field of international literary translations in order to cultivate a new subscriptionbased publishing model - and in so doing to 'curate' this neglected niche. Crucial to the sustainability of this model, according to Tobler (2013), has been finding 'a system of working that is genuinely open and collaborative.'(p. 9) He uses Robinson's description of an emergent 'digital publishing model' to describe how this works in practice, whereby “.... each content focused community, each Content Vertical, has the potential to establish its own brand in the eyes of the community it serves"' (Robinson, 2012, p. 13, cited in Tobler, 2013, p. 9). Tobler's observations from the helm of And Other Stories would seem to bear out the hypotheses offered by Bhaskar and Robinson. However, he also caveats his discussion with the observation that offline as opposed to digital networking has proven to be the key to effective collaboration in this context: 
'[T]he discussion is freer, more honest, and deeper. Just because digital helps to organise people together does not mean it improves everything' (p. 9). And despite achieving significant symbolic successes in the first year of operation, ${ }^{4}$ Tobler is candid about the risky commercial viability of such a specialist social enterprise within the larger ecosystem: 'while the new digital world opens up much trumpeted possibilities for small independents, capital is still required to take full advantage of those possibilities.' (10) He is referring to financial capital here, but in reflecting on how the 'content focused community' behind And Other Stories initially came together, it is evident that the viability of the enterprise hinged on their ability to leverage the aggregated social and cultural capitals produced through their creative collaboration, their 'labours of love', as he puts it:

Translators, editors, designers, and other publishing folk could meet up to share their great unpublished foreign books, and talk about the best ways to publish them here. Everyone would be able to get on with their task from their own computer/home/heated public library. And there would be plenty of opportunities to be involved: accounting, reading, editing, translating, selling and marketing, fundraising, advising on business or on the editorial committee, party-throwing, web or book design, etc. (Tobler, 2009, p. 25, cited in Tobler, 2013, p. 8).

The nature and outcomes of the collaborative production Tobler describes in these short articles align closely with what Adam Arvidsson (2013) calls 'collaborative publics', the organisational form par excellence of neoliberal cultural economy:

As ways of coordinating production, publics are different from markets and bureaucracies in that they allow for a wider range of concerns to serve as motivations. Knowledge workers are motivated by the prospect of economic gain, but also, as we move up the value chain, by possibilities for self-realisation, for having a meaningful impact, and for garnering peer recognition. (p. xi)

Such publics offer great potential for rebuilding and potentially also redistributing 'ethical value', in Arvidsson's discussion, and this is clearly the aspiration of Tobler and all those mutually invested in sustaining the success of And Other Stories. Authors who would otherwise not be known outside of their native language are introduced to international markets. The artistic value of translation as an integral creative input is recognised and promoted. This added value is returned to translators through increased legitimacy and fairer payment, and to the rest of the community in the self-realisation actuated through their contribution to the symbolic success of the collaborative enterprise - whether that is as a book designer doing work on the cheap (or for nothing), or a subscriber 
who gets to read their nominated author in English and see them potentially catapulted from peripheral obscurity to international recognition.

And Other Stories offers an instructive case study of the opportunities but also challenges presented to independent publishers by the collaborative cultures that attend digital convergence. In her discussion of this subject, Frania Hall (2014) explains that efforts to bridge the rift between the publisher as 'content machine' and as 'curator' requires acknowledgement of the nature and extent of existing collaboration among the creative disciplines that now converge in publishing. Hall notes that ' $[\mathrm{c}]$ ollaborative activity has been part and parcel of publishing throughout its history and essential to innovation whether one is developing new products or finding new ways to market, preparing major new digital initiatives or developing new operations' (p. 22). But this new and dynamic environment means that:

rather than collaborating with one main type of creative producer-the author-or with other suppliers from within the publishing industry space, like printers and software developers, publishers are now more often collaborating cross-creative sector, and doing so in new ways. The way that projects are financed, the number of players involved, the market places being considered, and the issues around ownership of intellectual property are becoming more complex in some of these new collaborations. The expected outcomes are also sometimes different; success and failure may be measured differently and collaborations may well be primarily exploratory rather than transactional. (p. 22)

Sarah Brouillette and Christopher Doody (2015) offer a more critical appraisal of this phenomenon. Publishing is no longer simply about book making or even the production of 'literature' as such. Rather, '[m] ost major publishers exist within enormous media conglomerates eager to see the literary endlessly repurposed.'(p. 99) In such a scenario the production - or rather, the relentless reproduction of the 'literary' in transmedia formats, most notably in the form of sprawling TV, film and video game franchises with their attendant merchandising and prosumer paratexts - requires unprecedented cooperation among a multitude of actors. Yet the collective nature of the creative labour responsible for creating the content is doubly occluded. First, through the marketing discourse of an industry that remains commercially wedded to the romantic notion of the author as solitary creative genius - or indeed as the author-brand, in the neoliberal manifestation of this trope. Second, by the mega-tech corporations who not only seek to exploit the value spread through collaborative publics, but who from their very outset have, as Arvidsson (2013) describes, constituted themselves around the accumulation of what he terms 'ethical capital' (p. 99).

In recent years numerous studies have critiqued the effect such dynamics have on the nature and experience of work across disciplines in the creative 
industries. These typically focus on the exploitation and self-exploitation involved in 'passionate work' (Arvidsson et al., 2010) and consider the ways and extent to which creative economy discourses normalise the exploitation of workers in a promotional culture that understands creative labour as a socially necessary mode of self-articulation, rather than solidarity (McGuigan 2014, Banks, Gill and Taylor 2014). These critiques have tended to focus on craft and screen-based media industries (e.g. Curtin's and Sanson's broadly-titled Precarious Creative: Global Media, Local Labor (2016) is almost exclusively concerned with television and cinema). One typically finds references to 'mass publishing' included in summary discussions (e.g. McKinlay and Smith, 2009, p. 11), but with the exception of Hesmondhalgh's and Baker's case study of work in the magazine industry (2009) the varied forms of cultural work and creative labour involved in publishing - especially as other creative disciplines increasingly converge in publishing - have received scant attention.

Tobler's (2013) précis of the activities and tasks required for a publishing startup - 'accounting, reading, editing, translating, selling and marketing, fundraising, advising on business or on the editorial committee, party-throwing, web or book design' (p. 8) - presents a scenario where book publication is made possible by a range of ancillary actors and activities not dissimilar to the 'collective activity' of what Howard Becker (1982) terms an 'art world'. 'Works of art, from this point of view,' writes Becker, 'are not the products of individual makers, "artists" who possess a rare and special gift. They are, rather, the joint products of all the people who cooperate via an art world's characteristic conventions to bring works like that in to existence.'(p. 35) Art worlds - not artists produce art works. Just as importantly, they also confer aesthetic value. This is a defining characteristic of the collaborative labour harnessed through the collective activity of the art world: 'the interaction of all the involved parties produces a shared sense of the worth of what they collectively produce.'(p. 39) Yet despite all the while acknowledging that this art world is cleaved by an 'extensive division of labour' (p. 13), Becker chooses to overlook what happens when this collectively produced aesthetic value, much like the similarly hypostatized 'ethical value' intrinsic to collaborative publics in Arvidsson's argument (Zwick, 2015. p. 401), is transmuted into exchange value by cultural economies dominated by competition among artist- (or in this case, author- and auteur-) brands. Needless to say, as the literature on cultural work and creative labour invariably attests, the symbolic and economic rewards of this competition are unequally distributed across this division.

Gregory Sholette (2003) provides an important corrective to Becker's depoliticised account of art worlds. He describes the creative labour that undergirds the art world as being structurally - which is to say, necessarily - occluded. What Becker terms 'support activities' (p. 5) and 'support personnel' (p. 17), Sholette figures as 'creative dark matter': a multitude which 'makes up the bulk of the artistic activity produced in our post-industrial society ... [but which] ... is invisible primarily to those who lay claim to the management and 
interpretation of culture - the critics, art historians, collectors, dealers, curators and arts administrators.'(p. 4) However for Sholette there exists immanent liberatory potential within this dark matter, or 'shadow creativity' as he also refers to it, which he traces in examples of amateur and specifically social art practice that 'displays a degree of autonomy from the critical and economic structures of the art world' (p. 6).

The examples of networked, collaborative production in independent book and magazine production that Alessandro Ludovico discusses in Post-Digital Print (2012) share the same semi-autonomy, and to an extent also the immanent liberatory potential of Sholette's 'dark matter'. For Ludovico, cultural production that is socialized through the networks characteristic of independent publishing enables critique and resistance: 'artists use networks as a platform for critical reflection and intervention within the global distribution structure (thus playing a major role in re-conceptualising it).' (p. 11) These networked practices are at the same time also instrumental for independent publishing as the specifically social enterprise Tobler describes, which by leveraging social and cultural capital inevitably sees a trade off between critical autonomy and the imperatives of the market:

"networking" also becomes synonymous with the "sharing" of cultural products - underexposed or otherwise invisible materials, whether printed or digital. Here, the individual reputation of each (known and shared) cultural product becomes a key factor in the success of a new business model established by the network. (p. 11)

As independent publishers respond to digital transformations by looking to incorporate and capitalise on this model of networked collaborative production, and even as they engage with participatory culture and acknowledge that the 'ethical value' of their literary products is co-produced among collaborative publics, what Alessandro Gandini (2016) terms 'reputational capital' - and so inevitably in this case the mark of the author-brand - retains a privileged position in the publishing ecosystem (Phillips 2014, p. 20).

Just as the title of John B. Thompson's study of the publishing industry, Merchants of Culture (2010), anticipates Brouillette's and Doody's discussion of contemporary publishing and the market imperative for adaptation, whereby the very notion of the literary has itself become a cultural industry, his exhaustive enquiry into the mechanics of how this plays out as publishers struggle against the forces of disintermediation points to the increasingly important promotional function played by the author-figure. In order to accumulate sufficient cultural capital to be consecrated as such, this figure must possess the strikingly paradoxical 'star' quality Joe Moran (2000) identifies in his discussion of North American authors in the late twentiethcentury. For Moran, 
literary celebrities cannot simply be reduced to their exchange value they are complex cultural signifiers who are repositories for all kinds of meanings, the most significant of which is perhaps the nostalgia for some kind of transcendent, anti-economic, creative element in a secular, debased, commercialized culture. (p. 9)

Only once they are elevated to this pedestal of supposed autonomy can the author become what Thompson terms the 'platform' - through which the gamut of their cultural and social capital might be commodified:

Essentially, platform is the position from which an author speaks - a combination of their credentials, visibility and promotability, especially through the media. It is those traits and accomplishments of the author that establish a pre-existing audience for their work, and that a publisher can leverage in the attempt to find a market for their book. (p. 86)

In what Thompson terms as 'a new economy of favours' (p.155), smaller, niche publishers look to carve a space in this new environment by leveraging their author-brand platforms as well as the social and cultural capital embedded in the products they promote. This is precisely what I witnessed at the 'Restless Derby' event in 2014. The most plausible reason for why Stefan Tobler (and also Vladislavić himself, for that matter) was happy for Vladislavić to promote Ponte City would be precisely because it leveraged Vladislavićs value as the kind of a cross-promotional 'platform' Thompson describes. It associated And Other Stories with the accumulated cultural capital of Vladislavićs career as a writer and as an influential editor who plays an instrumental role in both the realisation and consecration of artworks across a number of fields. Put a little less mechanistically, the event showed how the author was in fact an auteur.

\section{Collaborative networks, auteur authorship: Ponte City}

Vladislavić described Ponte City as one of 'his' books. Intriguingly, amazon. co.uk would seem to agree. Amazon's UK website lists the book as being 'by' and so one might be led to believe, authored by - Ivan Vladislavić. But then, it also credits authorship to the book's designer, Ramon Pez, and is indexed to both of their Amazon UK author pages (see fig. 5.4). On Amazon's US site, by contrast, the authorship is credited to Subotzky and Waterhouse with no mention at all of Vladislavić or Pez. In yet another credit iteration, the book is catalogued in the British Library with the following description: 'Title: Ponte City: Mikhael Subotzky, Patrick Waterhouse /edited by Ivan Vladislavić; [book] designed by Ramon Pez ; the Walther Collection.' These crediting discrepancies may be attributed to different cataloguing methods or simply mistakes in the 
metadata supplied by the publisher. But that the book's editor and designer are credited so prominently in the metadata, and that everyone who had a hand in its making is given a 'production' credit in the book, ${ }^{5}$ is a testament to how, in independent publishing generally and photobook publishing in particular, the typically hidden labour of what Becker might have termed 'support personnel' and Sholette calls 'shadow creativity' is increasingly acknowledged. And yet the copyright holder for the book is neither the prize-winning photographers nor the prize-winning editor, nor (one would imagine) the soon-to-be-awarded designer, but instead: Steidl Publishers. ${ }^{6}$

To those in this particular niche cultural industry the symbolic success of Ponte City no doubt confirms the powerful consecratory role of its pre-eminent publisher, Gerhard Steidl, ${ }^{7}$ a self-proclaimed craftsmen devoted to the artistic success of his clients. Steidl began work as a designer and publisher in 1967 and learnt screen printing from no less than Andy Warhol, publishing the first book under his own imprint in 1972 (Steidl, 2014). In their history of the artist's book, Janneke Adema and Gary Hall (2013) argue that the medium of the book proved instrumental in the politicization of artistic practice in the 1960s and 70 s counterculture, a context crucial for understanding Steidl's practices and ethos. The artist's book was democratic in the sense of being more widely available and accessible than traditional artistic outputs, but also radical in terms of offering an alternative exhibition space that fostered experimentation and artistic autonomy. As Steidl himself notes time and again in interviews, 'Books are commodities but can also be works of art if well made'. (Scheufelen, nd) Celebrated for its potential to dissolve distinctions between high and low culture, the artist's book was at the vanguard of what Adema and Hall, following Johanna Drucker (1995), term the 'democratic multiple': it's affordances are democratic, anti-institutional, but also reflexive: 'the book offered artists a space in which they were able to experiment with the materiality of the medium itself and with the practices that comprised it, and thus ultimately with the question of what constituted art and an art object.' (Adema and Hall, 2013, pp. 142-3) Steidl likewise insists the book is an inherently democratic medium and should not be produced in limited runs, but also that the books he makes are not 'industrial objects'. Under his exacting auteur-like command of the book-making process, the concept of the book is realized through the same assemblage of skills, materials and production technology 'as fine art printers use for limited edition prints' (Steidl, 2014). Steidl's seemingly contradictory belief in the nature of the book as democratic art object (in principle widely available yet designed as if for a field of restricted production) encapsulates the wider tensions observable in independent publishing.

The prominence given to the production network in the credits of Ponte City provides an example of how the independent publishing sector attempts to resist the (self-)exploitation of creative labour observable across the creative industries more generally (which, as discussed, increasingly converge in publishing). Very rarely are such books made with commercial success in 
mind. For those involved in their production - from the artists who provide the primary content to the craft professionals who play their part in assembling the book, aided and abetted by the intermediaries whose work it is to connect, cultivate and consecrate - the co-operative activity involved in realizing the artwork as a published book is integral to its aesthetic value. The high production values typical of this publishing format do not merely add an appealing lustre to what is an already rarefied art object (or tactility, or scent, though these are essential synaesthetic ingredients according to Steidl (Scheufelen nd)). Rather, they are intrinsic to the creation and circulation of value in a cultural economy that is structurally reliant on the collaborative productive input of a wide range of agents, intermediaries and institutions, and yet is dominated by the symbolic power of the auteur-figure as a crosspromotional platform.

\section{Conclusion}

The example of the social enterprise publisher And Other Stories - committed to the curation of translated literary fiction that might otherwise never come to the attention of English speakers - suggests that the auteur-figure serves a vital purpose. Coalescing in this figure is the aggregate cultural and social capital the platform - the independent publisher needs to cultivate the kind of productive consumer public, and indeed benefit from the nascent 'ethical economy', that Adam Arvidsson (2013) proposes. The success of Ivan Vladislavić in the case of Ponte City, as an auteur as opposed to 'just' an editor or even an author in the traditional sense, provides grounds for optimism. Having gained financial autonomy through a prize that consecrated him as an author in his own right, he continues to edit and invest in the work of others through his editorial craft and participation in joint projects made possible through the collaborative cultures and network practices of independent publishing. As an auteur he continues to provide a platform through which others might share in his success.

Steidl's practice of providing full production credits for his books similarly projects independent publishing as the kind of cooperative art world Howard Becker described. But Tobler's cautionary note concerning the necessity for a bare minimum of financial capital for the sustainability of And Other Stories, and Steidl's relationship with patrons ranging from Karl Largerfeld to the investment banker-turned private art collecter Artur Walther, remind us that this nascent 'ethical economy' is structurally imbricated in a neoliberal cultural economy where the symbolic and the economic dividends of ethical and aesthetic investments are typically both privatized and financialised.

It is in the making and promotion of photobooks such as Ponte City that we find perhaps the greatest concentration of intersecting modes of collaborative production across the creative industries: the 'post-digital' network practices of 
independent book and magazine publishing; the 'collaborative culture' but also the 'economy of favours' operative among smaller publishers in the publishing ecosystem; the aesthetic valorization intrinsic to the collective activity of an art world; and the reputational or ethical economy that emerges when this collective activity is expanded to incorporate a productive consumer public. Yet at the same time this case study also reveals the continued structural role played by the art world's 'shadow creativity' - the division of labour that is occluded precisely so the auteur figure can provide a coherent promotional platform to leverage the aggregate social and cultural capital embedded in the artwork.

\section{Notes}

1 The joke here being that fans would carry out the same project that animates the novel's anti-hero, retired editor Aubrey Terle - what he calls 'The Proofreaders Derby' (Reid, 2014).

2 This was not a one off. Before coming to the UK, Vladislavić gave an interview for the South African Leadership magazine where he includes Ponte City among the books he has helped 'conceptualise and commission' (Penfold 2014).

3 This conceit amplifies the design rationale provided in the introduction to the photobook, illustrating how over its 30-year history the building has served as a monumental screen on to which has been projected some of the city's most pervasive and powerful social myths; but also how it might be encountered otherwise - as a frame for the realization of dreams and desires of those who have actually lived in it, as well as the fears and anxiety of those who have not. Similar to the Restless Supermarket in some ways, Ponte City doesn't just document the geographical and social changes in Johannesburg from the twilight of apartheid to the present moment, it deconstructs the mythic layers of meaning the building has accrued by asking readers to engage in the writerly act of reconstructing the social history it embodies.

4 'Our first four authors were published in late 2011. From those four authors, Villalobos's Down the Rabbit Hole was the first translation ever to be shortlisted for the Guardian First Book Award and his 2013 Quesadillas was a winner of an English PEN Writers in Translation Award, while Deborah Levy's Swimming Home made the Man Booker Prize shortlist in 2012, and her 2013 story collection Black Vodka was shortlisted for the Frank O’Connor International Short Story Award.' (Tobler, 2013, p. 8).

${ }^{5}$ At least, one presumes the following credits, appearing on the final page of the photobook, are exhaustive:

Editing: Ivan Vladislavić

Book Design: Ramon Pez 
Research: Nadiva Schraibman

Interview transcription: Minky Schlesinger

Scans: Tjorven Bruyneel/Tony Meintjes

Separations: Steidl's digital darkroom

Production and printing: Steidl, Gottingen

Additional Production: Chantelle Booysen/Serame Metsing

Caitlin Pieters/Rebecca Simpson

(Ponte City 2014, p. xx)

${ }^{6}$ In the main photobook section of the book and the 17 accompanying pamphlets the same copyright details are provided:

(C) 2014 Mikhael Subotsky and Patrick Waterhouse for images

(C) 2014 individual authors for texts

(C) 2014 original copyright holders for archival material

(C) 2014 Steidl Publishers for this edition

${ }^{7}$ As well as the investment banker-turned art patron Artur Walther, who also receives credit for co-producing the book with Steidl - which no doubt means he underwrote what would have been extremely high production costs. Walther is reputed to have assembled the largest collection of African photography in the world (Doran 2015) and in 2011 nominated Subotzky and Waterhouse for the Rencontres d'Arles Discovery Award - which they duly won - for Ponte City. Although the book had not been published and the project itself not yet completed according to the timeframe given in the photobook introduction, 'Ponte City' was first installed at The Walther Collection in 2011 as part of the 'Appropriated Landscapes' exhibition curated by Corinne Disrennes (2011).

\section{References}

Adema, J. and Hall, G. (2013) The Political Nature of the Book: On Artists' Books and Radical Open Access (co-authored with Janneke Adema), New Formations, Number 78, Summer.

Arvidsson, A. (2013). The Ethical Economy: Rebuilding Value After the Crisis. Columbia, OH: Columbia University Press.

Arvidsson, A., Serpica, N., Malossi, G. (2010). Passionate work? Labour conditions in the Milan fashion industry. Journal for Cultural Research, 14(3), 259-309.

Banks, M., Gill, R. and Taylor, S. (2014). Theorizing Cultural Work. London: Routledge.

Becker, H. (1982). Art Worlds. Berkeley, CA: University of California Press.

Bourdieu, P., \& Johnson, R. (1993). The Field of Cultural Production: Essays on Art and Literature. Columbia, $\mathrm{OH}$ : Columbia University Press. 
Bhaskar, M. (2016). Curation: The Power of Selection in a World of Excess. London: Little, Brown

. (2013). The Content Machine: Towards a Theory of Publishing from The Printing Press to the Digital Network. New York: Anthem Press..

Brouillette, S. and Doody, C. (2015). The literary as a cultural industry. In Kate Oakley and Justin O'Conner (Eds.), The Routledge Companion to the Cultural Industries. London: Routledge.

Christensen, C. M. (1997) The Innovator's Dilemma: When New Technologies Cause Great Firms to Fail. Boston, Mass: Harvard Business School Press.

Curtin, M. and Sanson, K. (2016). Precarious Creativity: Global Media, Local Labor. Oakland, CA: University of California Press.

Disrennes, C. (2011). Appropriated landscapes. The Walther Collection, NeuUlm. Exhibition.

Doran, A. (2015). Photographic Memory: Artur Walther has built what may be the world's largest and most important private collection of African photography'. Online, 11 June. Retrieved from http://www.artnews. com/2015/11/06/photographic-memory-artur-walther-has-what-maybe-the-worlds-largest-and-most-important-private-collection-of-africanphotography-2.

Drucker, J. (1995) The Century of Artists' Books. New York, NY: Granary Books.

Gandini, A. (2016). The Reputation Economy: Understanding Knowledge Work in Digital Society. Palgrave Macmillan: London.

Hall, F. (2014). Digital convergence and collaborative cultures: Publishing in the context of the wider creative industries. Logo, vol. 25 (4): 20-31. DOI: 10.1163/1878-4712-11112055

Hesmondhalgh, D. and Baker, S. (2009). "A very complicated version of freedom": Conditions and experiences of creative labour in three cultural industries. Poetics 38, 4-20. DOI: 10.1016/j.poetic.2009.10.001

Ludovico, A. (2012). Post-Digital Print: The Mutation of Publishing since 1894. Santa Monica, CA: Ram Publications.

McGuigan, J. (2014). The neoliberal self. Journal of Current Cultural Research, 6: $1,223-40$.

McKinlay, A., \& Smith, C. (eds). (2009). Creative Labour: Working in the Creative Industries. Basingstoke: Palgrave Macmillan.

McQuivey, J. (2015). Publishing leaders happily disrupt themselves to avoid being disrupted. In Jeremy Greenfield (Ed.) Finding the Future of Digital Publishing. F+W Media Inc. Digital Book World.. . (2013). Digital Disruption: Unleashing the Next Wave of Innovation. Amazon Publishing.

Moran, J. (2000). Star Authors: Literary Celebrity in America. London: Pluto Press.

Murray, S. (2012). The Adaptation Industry: The Cultural Economy of Contemporary Literary Adaptation. New York and London: Routledge. 
Nash, R. (2013). What is the business of literature? Virginia Quarterly Review, 89: 2. Retrieved from http://www.vqronline.org/articles/what-businessliterature.

Penfold, G. (2014). 'Ivan Vladislavić: the most famous unknown', Leadership, 1 July. Retrieved from http://www.leadershiponline.co.za/articles/ivanVladislavić-11579.html.

Phillips, A. (2014) Turning the Page: The Evolution of the Book. Abingdon: Routledge.

Photographers Gallery, The (2015). 'About the Photography Prize'. Photographers Gallery, 10 April . Retrieved from http://thephotographersgallery.org. uk/3180/About-The-Photography-Prize/890

Reid, K. (2014 June 3). Register for the 2014 Derby - from 'The Restless Supermarket' by Ivan Vladislavić. Retrieved from: https://africainwords. com/2014/06/03/call-for-entries-the-2014-restless-derby-of-the-restlesssupermarket-by-ivan-Vladislavić-fame/

“The Restless Derby." Promotional event to support the UK publication of The Restless Supermarket and Double Negative (And Other Stories), with Ivan Vladislavić in conversation with Katie Reid, held at the University of Sussex. 24 June 2014.

Robinson, H. (2012.) Digital publishing: Does it herald a renaissance for the industry?, Logos: Journal of the World Publishing Community, 23: 4, 7-20.

Ruddick, G. (2015). Waterstones prepares for new chapter as bookshop chain returns to profitability. Guardian, 20 November. Retrieved from http:// www.theguardian.com/business/2015/nov/20/waterstones-profit-booksamazon.

Scheufelen, (nd). The scent of books: interview with Gerhard Steidl. Scheufelen. com. Retrieved from http://www.scheufelen.com/en/phoenix-ausgabe-0212/ the-scent-of-books-interview-with-gerhard-steidl.html

Sholette, G. (2003). Dark matter: activist art and the counter-public sphere. Retrieved from http://www.gregorysholette.com/wp-content/ uploads/2011/04/05_darkmattertwo1.pdf.

Steidl, G (2014). Gerhard Steidl: "I Turn Everything Upside Down” The Talks. 7 May. Retrieved from http://the-talks.com/interview/gerhard-steidl.

Tobler, S. (2013). And Other Stories: literary publishing as a social enterprise. Logos: Journal of the World Publishing Community, 24: 4, 7-11. . (2009). Supply + Demand + Magic. In Other Words, 33, 24-7.

Walkowitz. R. L. (2016). The persistence of books. World Literature Today. May. Retrieved from http://www.worldliteraturetoday.org/2016/may/persistence-books-rebecca-l-walkowitz.

Zwick, D. (2013). Utopias of ethical economy: A response to Adam Arvidsson. Ephemera: Theory and Politics in Organization, 13: 2, 393-405. 
